\title{
A PLANIFICAÇÃO ECOLÓGICA COMO UM INSTRUMENTO PARA PROMOVER DE FORMA DEMOCRÁTICA E EFICIENTE A SUSTENTABILIDADE DA AGRICULTURA
}

\author{
Benedito Silva Neto
}

\begin{abstract}
RESUMO
O artigo tem como objetivo demonstrar que uma planificação ecológica pode se constituir em um instrumento para uma promoção democrática e eficiente da sustentabilidade da agricultura. O referencial teórico adotado no artigo é baseado na obra de Györg Lukács dedicada a ontologia do ser social. Este referencial fundamentou a elaboração de um modelo de programação linear, cujas características são discutidas por meio da análise da sua estrutura formal e de exemplos numéricos. O pressuposto sobre o qual se baseia a formulação do modelo, de que as riquezas sociais, na forma de produtos para consumo final, meios de produção e recursos naturais, são variáveis exógenas que devem ser definidas por decisões políticas, permite demonstrar que o modelo é compatível com um processo democrático de planificação. Conclui-se que uma planificação ecológica pode se constituir em um instrumento eficiente e democrático para a promoção da sustentabilidade da agricultura, permitindo evitar medidas que, embora aparentemente compatíveis com a promoção da sustentabilidade, podem ser contraditórias com este objetivo, respondendo apenas a interesses específicos de determinadas classes sociais.
\end{abstract}

Palavras-chave: sustentabilidade, planificação democrática, modelo de planificação.

\section{ECOLOGICAL PLANNING AS AN INSTRUMENT TO DEMOCRATICALLY AND EFFICIENTLY PROMOTE AGRICULTURE SUSTAINABILITY}

\begin{abstract}
The article aims to demonstrate that ecological planning can be an instrument for a democratic and efficient promotion of agriculture sustainability. The theoretical framework adopted in the article is based on the work of Györg Lukács dedicated to the ontology of the social being. This theoretical framework was the basis for the development of a linear programming model, whose characteristics are discussed through the analysis of its formal structure and numerical examples. The assumption on which the formulation of the model is based, that social wealth, in the form of products for final consumption, means of production and natural resources, are exogenous variables that must be defined by political decisions, permits to demonstrate that the model is compatible with a democratic planning process. It is concluded that an ecological planning can constitute an efficient and democratic

1 Graduado em Agronomia (UNESP/Jaboticabal). Mestrado em Produtividade e Biodinâmica do Solo (UFSM). Doutorado em Desenvolvimento Agrícola (INA-PG/França). Professor do Programa de Pós-Graduação em Desenvolvimento e Políticas Públicas da Universidade Federal da Fronteira Sul (UFFS). E-mail: bsilva@uffs.edu.br.
\end{abstract}


instrument for the promotion of the sustainability of agriculture, allowing to avoid measures that, although apparently compatible with the promotion of sustainability, can be contradictory with this objective, responding only to specific interests of certain social classes.

Keywords: sustainability, democratic planning, planning model.

\section{INTRODUÇÃO}

Diante da urgente necessidade de medidas para a promoção da sustentabilidade das sociedades contemporâneas, alguns autores (LÖWY, 2008; HUSSON, 2019; SILVA NETO, 2017, p. 211) e até mesmo algumas formações políticas, especialmente na Europa (BILLARD, 2016; LÉVARD, 2016), têm proposto a implantação de uma planificação ecológica da economia. Tal posicionamento, porém, contrasta com o de autores que atribuem um caráter tecnocrático e produtivista intrínseco a todo processo de planificação (TOMJO, 2013). O presente artigo tem como objetivo demonstrar que uma planificação ecológica pode se constituir em uma forma eficiente de conduzir um debate democrático sobre os padrões tecnológicos mais adequados para promoção da sustentabilidade da agricultura, rompendo com o produtivismo característico do pensamento econômico hegemônico que tem como pressuposto a necessidade de um ininterrupto crescimento econômico. Neste sentido, como discutido no artigo, tal planificação é indissociável de um combate sistemático à influência do poder econômico das classes dominantes exercido sobre as decisões coletivas que dizem respeito a produção e ao uso das riquezas sociais.

O referencial teórico adotado no artigo é baseado na obra de Györg Lukács dedicada à ontologia do ser social, desenvolvida no âmbito do materialismo histórico. Este referencial fundamentou a elaboração de um modelo de programação linear, proposto originalmente por Silva Neto (2018). Este artigo é dividido em quatro seções, além desta introdução e das considerações finais. O referencial teórico é apresentado na primeira seção. Na segunda seção é analisada a estrutura formal do modelo procurando-se demonstrar a possibilidade do estabelecimento de um sistema democrático de planificação ecológica. Na terceira seção são apresentadas a formulação e a solução básica de um exemplo numérico, com o objetivo de ilustrar as principais características do modelo geral apresentado anteriormente. A partir deste exemplo, na quarta seção são analisadas as possíveis consequências de dois tipos de política de preços para a promoção da sustentabilidade, a primeira baseada em impostos e a segunda na definição de demandas específicas de produtos gerados com técnicas alternativas.

\section{REFERENCIAL TEÓRICO}

Lukács (2011) analisa o que ele denomina de "complexos de problemas mais importantes" relativos ao que essencialmente caracteriza o ser humano enquanto tal, ou seja, o que caracteriza a sua natureza ontológica. O complexo de problemas prioritário é o trabalho. É importante salientar que a prioridade ontológica acordada ao trabalho, porém, é vista como um "complexo" o que é explicado pelo autor como,

Deve-se (...) rejeitar qualquer "dedução ontológica" do edifício, do ordenamento das categorias (aqui os valores), partindo do seu conceito geral, abstratamente apreendido. (...) Deve-se rejeitar, do mesmo modo, a ontologia vulgar-materialista que vê 
as categorias mais complexas como simples produtos mecânicos das mais elementares e fundantes e, desse modo, por um lado, obstrui para si mesma toda compreensão da particularidade das primeiras e, por outro, cria entre as primeiras e as segundas uma falsa hierarquia, supostamente ontológica, segundo a qual só se pode atribuir um ser em sentido próprio às categorias mais simples. (LÚKACS, 2011, p. 147).

O trabalho, como relação característica dos seres humanos com a natureza, sempre mediada por relações dos seres humanos entre si (relações sociais), assim, constitui-se no processo fundamental da atividade econômica (MARX, 1999 [1867] p. 212, LUKÁCS, 2009, p. 75). Neste sentido, o processo de trabalho integra dois aspectos distintos. O primeiro é uma posição teleológica, ou seja, a concepção do objeto a ser produzido. O segundo é a manipulação dos processos causais que possibilitam a fabricação do objeto concebido. É, portanto, no processo material e histórico de trabalho que se consuma a distinção entre sujeito e objeto pelo ser humano (LUKÁCS, 2009, p. 75). Esta subjetividade, sem a qual os processos de trabalho não poderiam ser modificados, adquirindo assim seu caráter histórico, implica que certa liberdade é inerente a toda atividade econômica. O processo de trabalho, portanto, não é determinado mecanicamente pelas condições materiais existentes. Quanto maior o domínio dos processos causais pelos seres humanos, maior a diversidade de objetos que podem ser produzidos, assim como dos processos causais que podem ser mobilizados para produzi-los e, portanto, maior a possibilidade de escolha do ser social (LUKÁCS, 2011, p. 205).

Nas condições históricas do capitalismo, porém, o trabalho se torna alienado. Nestas condições, o trabalhador deixa de identificar na sua própria atividade a origem das riquezas por ele produzidas, atribuindo-as ao capital. Ontologicamente, no entanto, o ser humano não pode ser reduzido a um simples meio de produção, voltado para a acumulação de capital, embora ele historicamente o seja no capitalismo. Esta prioridade ontológica do trabalho sobre o capital é expressa pela teoria do valor de Marx (1999, [1867]), segundo a qual os preços e, portanto, os processos econômicos baseados em relações monetárias, não podem ser concebidos de outra forma senão como o produto de uma agregação de valor monetário baseada no tempo de trabalho socialmente necessário à produção.

\section{ESTRUTURA FORMAL DE UM SISTEMA DE PLANIFICAÇÃO ECOLÓGICA DEMOCRÁTICA}

A elaboração do modelo apresentado neste trabalho baseia-se nesses referenciais teóricos, que afirmam uma prioridade ontológica do trabalho na análise dos processos econômicos, com os aspectos subjetivos que isto implica. Assim de acordo com tal referencial, consideramos que a compatibilidade do sistema de planificação ecológica proposto neste trabalho com a determinação dos processos econômicos por decisões políticas, tomadas no capitalismo por meio da luta de classes, é a sua característica mais importante. Neste sistema, as decisões sobre a produção e o acesso ao consumo das riquezas sociais, produzidas pelo trabalho ou fornecidas pela natureza, devem ser tomadas anteriormente ao desencadeamento dos processos econômicos propriamente ditos que, por meio de um sistema de preços, permitiriam orientar o comportamento dos agentes econômicos que atuam nas unidades de produção. Neste sentido, não seriam os processos econômicos que determinariam as decisões a serem tomadas sobre as riquezas sociais, mas o inverso, 
com os processos econômicos desempenhando um papel meramente operacional, posteriormente a tais decisões.

Outra característica importante dessa planificação ecológica é que ela deve permitir uma análise objetiva das consequências do perfil da demanda e do nível do consumo de produtos finais, da geração de excedentes de meios de produção necessários para um futuro aumento da produção (se este for considerado desejável), assim como da quantidade de recursos naturais considerada aceitável de ser explorada. No quadro dessa planificação, a avaliação dessas consequências é realizada considerando o universo das técnicas disponíveis, assim como a diversidade das condições de produção. Todas as variáveis do modelo correspondem a fluxos e não a estoques, inclusive as relativas aos recursos naturais.

Enfim, o referencial teórico adotado implica que o tempo de trabalho socialmente necessário deve ser o principal agregado a ser considerado no modelo. Em termos matemáticos, o tempo socialmente necessário à produção significa o menor tempo de trabalho necessário para a satisfação da demanda de produtos de consumo final e de meios de produção.

A partir das considerações realizadas nos parágrafos anteriores, o problema primal do modelo foi formulado como,

$$
\text { Função objetivo: minimizar } \sum c_{i}^{l} q_{i}^{l}+\sum c_{z}^{x} k_{z}^{x}
$$

$$
\text { Sujeito às restrições }
$$

$$
\begin{gathered}
\sum q_{i}^{l} \geq D_{i} \\
\sum k_{z}^{x}-\sum a_{i z}^{l} q_{i}^{l} \geq K_{z} \\
\sum \sigma_{j z}^{x} k_{z}^{x} \leq R_{j}
\end{gathered}
$$

onde temos,

$c_{i}^{l}=$ quantidade $(c)$ de trabalho por unidade do produto $(i)$ com a técnica $(I)$.

$q_{i}^{l}=$ quantidade $(q)$ do produto $(i)$ fabricado com a técnica $(I)$.

$c_{Z}^{x}=$ quantidade $(c)$ de trabalho por unidade de meio de produção $(z)$ gerado com a técnica $(x)$.

$k_{Z}^{x}=$ quantidade $(k)$ do meio de produção $(z)$ gerado com a técnica $(x)$.

$D_{i}=$ quantidade demandada $(D)$ de produto $(i)$.

$K z=$ quantidade $(K)$ do meio de produção $(z)$ excedente para reprodução ampliada (reprodução simples $K=0$ )

$a_{i z}^{l}=$ quantidade $(a)$ do meio de produção $(z)$ necessária para produzir uma unidade do produto $(i)$ com a técnica $(I)$.

$\sigma_{j z}^{x}=$ quantidade $(\sigma)$ de recurso natural $(j)$ necessário para a produção do meio de produção $(z)$ com a técnica $(x)$.

$R_{j}=$ quantidade máxima $(R)$ a ser utilizada do recurso natural $(j)$.

O problema dual, deduzido do do problema primal, fornece os preços dos produtos de consumo final, dos meios de produção gerados pelo trabalho e dos recursos naturais, que maximizam o valor agregado monetário, considerando a demanda de produtos, a disponibilidade de recursos e as condições técnicas de produção. Ele é formulado como,

Função objetivo: maximizar $\sum D_{i} p_{i}+\sum K_{z} \beta_{z}-\sum R_{j} r_{j}$

$$
\begin{aligned}
& p_{i}-\sum a_{i z}^{l} \beta_{z} \leq c_{i}^{l} \\
& \beta_{z}-\sum \sigma_{j z}^{x} r_{j} \leq c_{z}^{x}
\end{aligned}
$$


onde, além das variáveis do problema primal, já descritas, temos,

$p_{i}=$ preço $(p)$ do produto $(i)$.

$\beta_{z}=$ preço $(\beta)$ do meio de produção $(z)$ (gerado pelo trabalho).

$r_{j}=$ preço $(r)$ do recurso natural $(j)$.

De acordo com o teorema da dualidade, com as soluções ótimas temos,

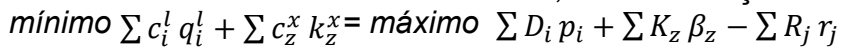

Nesse modelo, as variáveis relativas às riquezas correspondentes aos produtos de consumo final $(D)$, ao excedente de meios de produção necessários ao crescimento econômico $(K)$ e aos recursos naturais $(R)$, são variáveis exógenas. Isto significa que a quantidade e o tipo dos produtos de consumo final, o crescimento (ou eventualmente até mesmo um decrescimento) da produção e a exploração dos recursos naturais são considerados como decisões políticas, que não podem ser definidas pelo próprio modelo. Neste ponto é importante salientar a diferença deste modelo com os elaborados no âmbito da escola neoclássica, os quais são formulados para otimizar a alocação dos recursos e a distribuição das riquezas na sociedade, negando o seu caráter político (GUERRIEN, 1989). Por outro lado, é evidente que as restrições técnicas que determinam as consequências de cada escolha não podem ser negligenciadas. Mas é importante salientar que tais restrições jamais podem decidir, por si sós, o que uma sociedade considera mais desejável em relação às suas riquezas. Assim, se uma sociedade considera mais importante diminuir seus problemas ambientais, por meio da diminuição do consumo de produtos finais ou por meio da elaboração desses produtos com meios de produção menos exigentes em recursos naturais ou com menores quantidades de insumos agressivos à saúde humana e ao ambiente, o modelo fornece as técnicas e os preços correspondentes a tais decisões. Evidentemente, os problemas que podem ser causados pela diminuição do consumo de produtos finais para baixar o uso de recursos naturais, ou o maior tempo de trabalho em geral exigido por técnicas menos agressivas à saúde humana e ao ambiente, são efeitos negativos que devem ser analisados em relação aos benefícios de tais decisões. A planificação ecológica pode evidenciar tais efeitos possibilitando que as decisões coletivas possam ser tomadas de maneira consciente das suas consequências. No entanto, é importante salientar, mais uma vez, que a planificação desempenha um papel meramente operacional nesse processo. Esses aspectos da planificação ecológica são ilustrados pelo exemplo numérico discutido na próxima seção.

\section{FORMULAÇÃO E SOLUÇÃO BÁSICA DO EXEMPLO NUMÉRICO}

O exemplo foi elaborado a partir de observações do comportamento das culturas do milho (cultura $a$ ) e da batata doce (cultura $b$ ) nas condições do Noroeste do Rio Grande do Sul, conduzidos de acordo com diferentes padrões tecnológicos (SILVA NETO, 2013). No entanto, salientamos que os dados apresentados servem apenas para evidenciar possíveis contradições, e discutir as suas consequências sobre as propostas de desenvolvimento e promoção da sustentabilidade da agricultura, e não representar uma situação específica. No exemplo numérico são consideradas as duas culturas agrícolas mencionadas, produzidas a partir de dois meios de produção, agrotóxicos e combustível, os quais, por sua vez, são gerados a partir de um recurso natural, o petróleo. Cada cultura pode ser produzida por duas técnicas, 
convencional e alternativa. As características de cada cultura, (a) e (b), são apresentadas na tabela 1 .

Tabela 1 - Características das culturas consideradas para a elaboração do modelo

\begin{tabular}{|c|c|c|c|c|}
\hline & \multicolumn{2}{|c|}{ Cultura (a) } & \multicolumn{2}{|c|}{ Cultura (b) } \\
\hline & $\begin{array}{c}\text { Técnica } \\
\text { convencional } \\
\end{array}$ & $\begin{array}{c}\text { Técnica } \\
\text { alternativa }\end{array}$ & $\begin{array}{c}\text { Técnica } \\
\text { convencional }\end{array}$ & $\begin{array}{c}\text { Técnica } \\
\text { alternativa }\end{array}$ \\
\hline $\begin{array}{l}\text { Tempo de } \\
\text { trabalho (h/ha) }\end{array}$ & 4 & 25 & 30 & 50 \\
\hline Produção (t/ha) & 8 & 5 & 25 & 10 \\
\hline $\begin{array}{l}\text { Agrotóxicos } \\
(\mathrm{l} / \mathrm{ha})\end{array}$ & 30 & 12 & 115 & 22 \\
\hline $\begin{array}{l}\text { Combustível } \\
\text { (l/ha) }\end{array}$ & 100 & 60 & 180 & 50 \\
\hline
\end{tabular}

Fonte: elaborado pelo autor

Observa-se na tabela 1 que a cultura (a) possui características mais "extensivas" (produção de grãos) e a cultura $(b)$ características mais "intensivas" (horticultura), em função do menor e maior, respectivamente, emprego de meios de produção e de tempo de trabalho. Observa-se também na tabela 1 que as técnicas alternativas exigem o emprego de mais tempo de trabalho e proporcionam uma produção menor por superfície em relação às técnicas convencionais, mas exigem menos agrotóxicos e combustível (e, portanto, exigem também menos petróleo).

A partir dos dados mostrados na tabela 1 e considerando as exigências de trabalho e de petróleo para a produção dos agrotóxicos e de combustível, foi elaborada a tabela 2 , que mostra os coeficientes empregados para a elaboração do modelo básico.

Tabela 2 - Coeficientes do modelo básico

\begin{tabular}{|c|c|c|c|c|c|c|}
\hline & \multicolumn{2}{|c|}{ Cultura (a) } & \multicolumn{2}{|c|}{ Cultura (b) } & \multirow[t]{2}{*}{$\begin{array}{l}\text { Agro- } \\
\text { tóxico } \\
\end{array}$} & \multirow[t]{2}{*}{$\begin{array}{c}\text { Com- } \\
\text { bustível }\end{array}$} \\
\hline & $\begin{array}{c}\text { Técnica } \\
\text { conven- } \\
\text { cional }\end{array}$ & $\begin{array}{c}\text { Técnica } \\
\text { alterna- } \\
\text { tiva }\end{array}$ & $\begin{array}{l}\text { Técnica } \\
\text { conven- } \\
\text { cional }\end{array}$ & $\begin{array}{l}\text { Técnica } \\
\text { altern- } \\
\text { ativa }\end{array}$ & & \\
\hline $\begin{array}{l}\text { Tempo de } \\
\text { trabalho }(\mathrm{h} / \mathrm{t})\end{array}$ & 0,5 & 5 & 1,2 & 5,5 & 1 & 0,2 \\
\hline $\begin{array}{l}\text { Agrotóxico } \\
(\mathrm{l} / \mathrm{t})\end{array}$ & 3,75 & 2,4 & 4,6 & 2,2 & & \\
\hline $\begin{array}{l}\text { Combustível } \\
(1 / \mathrm{t})\end{array}$ & 12,5 & 12 & 7,2 & 5 & & \\
\hline $\begin{array}{l}\text { Petróleo }(\mathrm{I} / \mathrm{I}) \\
\text { Terra (ha/t) }\end{array}$ & 0.125 & 02 & 0.04 & 01 & 2 & 1,5 \\
\hline
\end{tabular}

Fonte: elaborado pelo autor

Assim, por exemplo, o coeficiente de 0,5 hora por hectare necessária para a condução da cultura (a) com a técnica 1 , mostrado na tabela 2 , foi obtido pela divisão das 4 horas por hectare necessárias para a condução da cultura (a) com a técnica 1 , pelo rendimento de 8 toneladas por hectare por ela proporcionado.

Observa-se na tabela 2 que as características das culturas, extensivas ou intensivas, sem mantêm, mas, desta vez, em relação a unidade de produto gerada e não mais em relação à superfície cultivada, mostrada na tabela 1. Da mesma forma, o coeficiente de 3,75 litros por hectare de agrotóxicos, mostrado na tabela 2, foi obtido pela divisão dos 30 litros de agrotóxico exigidos por hectare pelas 8 toneladas por hectare de rendimento, relativos a cultura (a) conduzida de acordo com a técnica 1 , 
mostrados na tabela 1. Neste sentido, observa-se que as diferenças entre as técnicas são maiores para a cultura $(b)$ do que para a $(a)$, especialmente no que diz respeito a economia de meios de produção e, portanto, do recurso natural.

A partir dos coeficientes mostrados na tabela 2 foi elaborado o problema primal do modelo. A solução do problema primal fornece a quantidade a ser produzida com cada técnica que minimiza o valor em tempo de trabalho, consideradas a demanda dos produtos e a limitação da extração de petróleo por ciclo de produção, e a área de terra. O problema primal foi formulado como,

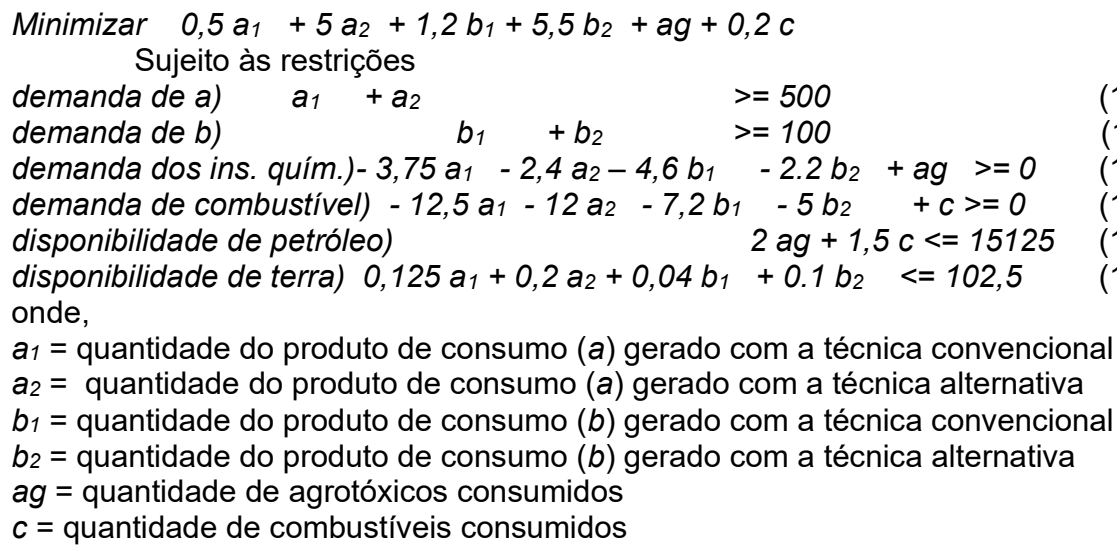

A partir do problema primal foi obtido o problema dual do modelo, o qual fornece os preços dos produtos e as rendas relacionadas à exploração do petróleo e ao uso da terra. O problema dual foi formulado como,

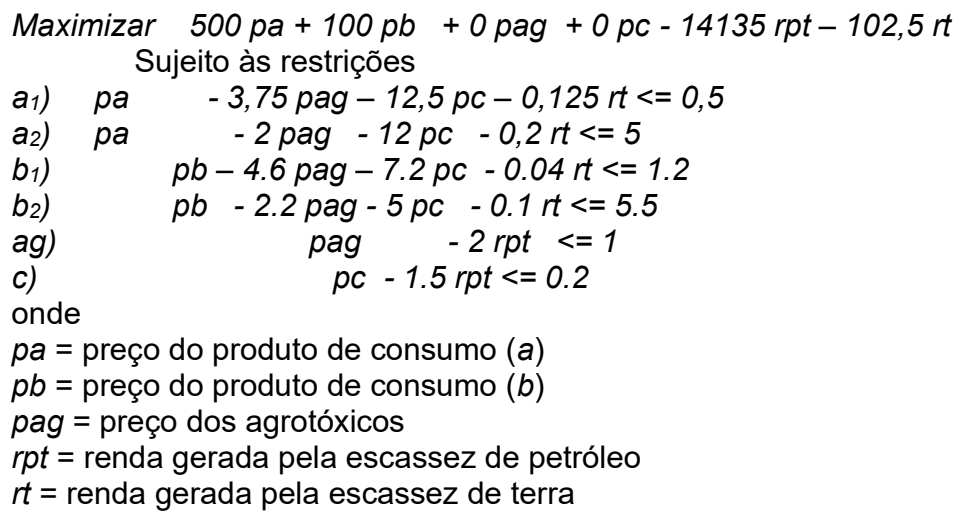


unidades. A abundância de petróleo e de terra explica a ausência de rendas relacionadas a estes recursos naturais.

Tabela 3 - Principais resultados obtidos pela solução do modelo básico (sem restrições ao uso de insumos e recursos naturais).

\begin{tabular}{|c|c|c|}
\hline & $\begin{array}{l}\text { Produção ou consumo } \\
\text { (físico) }\end{array}$ & $\begin{array}{l}\text { Valor, preço ou renda } \\
\text { (monetário) }\end{array}$ \\
\hline $\begin{array}{l}\text { Tempo de trabalho e valor } \\
\text { agregado }\end{array}$ & 4099 & 4099 \\
\hline $\begin{array}{l}\text { Produto de consumo (a) } \\
\text { gerado com a técnica }\end{array}$ & 500 & \\
\hline $\begin{array}{l}\text { convencional } \\
\text { Produto de consumo (a) }\end{array}$ & & 6,75 \\
\hline $\begin{array}{l}\text { gerado com a técnica } \\
\text { alternativa }\end{array}$ & 0 & \\
\hline $\begin{array}{l}\text { Produto de consumo (b) } \\
\text { gerado com a técnica }\end{array}$ & 100 & \\
\hline $\begin{array}{l}\text { convencional } \\
\text { Produto de consumo (b) } \\
\text { gerado com a técnica } \\
\text { alternativa }\end{array}$ & 0 & 7,24 \\
\hline Agrotóxicos & 2335 & 1 \\
\hline Combustiveis & 6970 & 0,2 \\
\hline Petróleo & 15125 & 0 \\
\hline $\begin{array}{l}\text { Terra cultivada (área e } \\
\text { renda) }\end{array}$ & 66,5 & 0 \\
\hline
\end{tabular}

Fonte: elaborado pelo autor

$\mathrm{Na}$ tabela 4 são mostrados os resultados econômicos que seriam obtidos com os preços e as rendas mostradas na tabela 3, considerando a aplicação de oito horas de trabalho. Observa-se na tabela 4 que os produtos das culturas gerados pelas técnicas convencionais, assim como a produção de agrotóxicos e combustíveis, proporcionam um valor agregado correspondente às oito horas de trabalho aplicado diretamente para desenvolvê-las. Observa-se na tabela 4 que a produção da cultura (a) com a técnica alternativa proporcionaria apenas 3,12 unidades monetárias e a da cultura $(b)$, também com a técnica alternativa, apenas 5,88 unidades monetárias, o que indica que estas técnicas não são socialmente necessárias (assim como o tempo de trabalho que seria aplicado por meio delas).

Estes resultados mostram que o valor agregado é um critério microeconômico de alocação de recursos coerente com as decisões políticas que seriam tomadas em nível macroeconômico. Como pode ser observado na tabela 4, o mesmo ocorre com o montante absoluto do lucro, o qual é diretamente proporcional ao valor agregado. Assim, os resultados da tabela 4 mostram que, tomando como critério de decisão o valor agregado (ou o lucro absoluto), os preços definidos por meio do modelo induzem os produtores a adotar as técnicas que são compatíveis com as decisões coletivas sobre as riquezas (como a demanda de produtos finais e os recursos naturais a serem empregados) baseadas em processos extra econômicos. É por esta razão que as técnicas da base ótima e os preços definidos pelo modelo são denominados eficientes. Por outro lado, como pode ser observado na tabela 4 , a taxa de lucro não pode ser considerada como um critério seguro para a escolha de técnicas eficientes, pois, para o produto de consumo $(b)$, a maior taxa de lucro é obtida pela técnica alternativa, que neste caso não é eficiente. 
Tabela 4 - Resultados obtidos com a aplicação de oito horas de trabalho a partir do modelo básico

\begin{tabular}{|c|c|c|c|c|c|c|}
\hline & \multicolumn{2}{|c|}{$\begin{array}{l}\text { Produto de consumo } \\
\text { (a) }\end{array}$} & \multicolumn{2}{|c|}{$\begin{array}{l}\text { Produto de } \\
\text { consumo (b) }\end{array}$} & \multirow[t]{2}{*}{$\begin{array}{l}\text { Agro- } \\
\text { tóxicos }\end{array}$} & \multirow[t]{2}{*}{$\begin{array}{c}\text { Com- } \\
\text { bustível }\end{array}$} \\
\hline & $\begin{array}{c}\text { Técnica } \\
\text { conven- } \\
\text { cional }\end{array}$ & $\begin{array}{l}\text { Técnica } \\
\text { alter- } \\
\text { nativa }\end{array}$ & $\begin{array}{l}\text { Técnica } \\
\text { conven- } \\
\text { cional }\end{array}$ & $\begin{array}{c}\text { Técnica } \\
\text { alterna- } \\
\text { tiva }\end{array}$ & & \\
\hline Produção & 16 & 1,6 & 6,67 & 1,45 & & \\
\hline $\begin{array}{l}\text { Valor da } \\
\text { produção }\end{array}$ & 108 & 10,8 & 48,27 & 10,53 & & \\
\hline Agrotóxicos & 60 & 3,84 & 30,67 & 3,2 & 8 & \\
\hline $\begin{array}{l}\text { Valor dos } \\
\text { agrotóxicos }\end{array}$ & 60 & 3,84 & 30,67 & 3,2 & 8 & \\
\hline Combustíveis & 200 & 19,2 & 48 & 7,27 & & 40 \\
\hline $\begin{array}{l}\text { Valor dos } \\
\text { combustíveis } \\
\text { Renda do } \\
\text { petróleo }\end{array}$ & 40 & 3,84 & 9,6 & 1,45 & & 8 \\
\hline Renda da terra & 0 & 0 & 0 & 0 & & \\
\hline Valor agregado & 8 & 3,12 & 8 & 5,88 & 8 & 8 \\
\hline Salário & 3 & 3 & 3 & 3 & 3 & 3 \\
\hline Lucro & 5 & 0,12 & 5 & 2,88 & 5 & 5 \\
\hline Taxa de lucro & $4,85 \%$ & $1,12 \%$ & $11,56 \%$ & $37,58 \%$ & $166,67 \%$ & $166,67 \%$ \\
\hline $\begin{array}{l}\text { V. agregado + } \\
\text { rendas }\end{array}$ & 8 & 3,12 & 8 & 5,88 & 8 & 8 \\
\hline $\begin{array}{l}\text { Taxa de lucro + } \\
\text { rendas }\end{array}$ & $4,85 \%$ & $1,12 \%$ & $11,56 \%$ & $37,58 \%$ & $166,67 \%$ & $166,67 \%$ \\
\hline
\end{tabular}

Fonte: elaborado pelo autor

\section{ANÁLISE DE MEDIDAS PARA A PROMOÇÃO DA SUSTENTABILIDADE}

Supondo agora que, diante de problemas ambientais e sanitários como a poluição e o aquecimento global provocado pelo intenso uso de combustíveis fósseis e a diminuição da biodiversidade e os danos à saúde humana provocados pelos agrotóxicos, uma sociedade deseje diminuir o uso desses insumos, assim como o de combustíveis fósseis. Uma proposta comumente protagonizada para atingir este objetivo é a diminuição do consumo de produtos finais, cuja produção seria baseada em técnicas mais simples, ou seja, "baixas tecnologias" (BILHOUIX, 2014). O argumento é que uma sociedade mais frugal poderia mais facilmente suprir as suas necessidades por meio de técnicas poupadoras de meios de produção e recursos naturais. No entanto, a simples diminuição do consumo de produtos finais, embora provocasse uma diminuição do uso de agrotóxicos e de combustíveis (na medida em que haveria uma queda da produção em geral) não implica em qualquer restrição ao uso das técnicas convencionais. Ao contrário, no caso do petróleo ser escasso, a diminuição do consumo poderia até viabilizar uma intensificação do uso dessas técnicas, na medida em que o petróleo passaria a ser relativamente mais abundante.

Outra forma de diminuir o uso desses insumos seria restringir o consumo de petróleo (o qual é empregado para a produção de agrotóxicos e combustíveis, como mostra a expressão (14)). No entanto, isto teria o inconveniente de afetar outros setores da economia de forma imprevisível por meio do modelo, que diz respeito apenas à agricultura.

Duas medidas para a diminuição do uso de agrotóxicos e, consequentemente, de petróleo na agricultura, as quais não apresentam os inconvenientes discutidos nos parágrafos anteriores, seriam o aumento do preço dos agrotóxicos por meio de 
impostos ou a definição de uma demanda específica dos produtos alternativos, o que permite Ihes atribuir um preço específico. Estas duas medidas são analisadas a seguir, iniciando pelos impostos, cujos resultados são mostrados nas tabelas 5 a 7 .

O nível de tais impostos compatível com a quantidade que se deseja diminuir do uso de agrotóxicos pode ser facilmente calculado por meio do modelo. Para tanto, basta introduzir no problema primal uma restrição à quantidade de agrotóxicos a ser utilizada. No problema dual isto implica uma variável que expressa o surgimento de uma renda gerada pela escassez dos agrotóxicos, a qual corresponde ao imposto a ser cobrado. Para ilustrar este caso, consideremos os resultados obtidos com uma limitação de $30 \%$ do uso dos agrotóxicos, o qual passa, assim, das 2335 unidades mostradas na tabela 3 para 1634,5 unidades. Os resultados obtidos são apresentados na tabela 5.

Tabela 5 - Principais resultados obtidos com a solução do modelo considerando um limite ao uso de agrotóxicos de 1634,5 litros.

\begin{tabular}{|c|c|c|}
\hline & $\begin{array}{l}\text { Produção ou consumo } \\
\text { (físico) }\end{array}$ & $\begin{array}{c}\text { Valor, preço ou renda } \\
\text { (monetário) }\end{array}$ \\
\hline $\begin{array}{l}\text { Tempo de trabalho e valor } \\
\text { agregado }\end{array}$ & 5285,39 & 5285,39 \\
\hline $\begin{array}{l}\text { Cultura (a) convencional } \\
\text { Cultura (a) alternativa }\end{array}$ & $\begin{array}{l}158,89 \\
341,11\end{array}$ & 15,22 \\
\hline $\begin{array}{l}\text { Cultura (b) convencional } \\
\text { Cultura (b) alternativa }\end{array}$ & $\begin{array}{c}0 \\
100\end{array}$ & 13,67 \\
\hline Agrotóxicos & 1634,5 & 3,26 \\
\hline $\begin{array}{llr}\text { Imposto } & \text { sobre } & \text { os } \\
\text { agrotóxicos } & & \end{array}$ & & 2,26 \\
\hline $\begin{array}{l}\text { Combustíveis } \\
\text { Petróleo }\end{array}$ & $\begin{array}{l}6579,44 \\
13138,7\end{array}$ & $\begin{array}{c}0,2 \\
0\end{array}$ \\
\hline $\begin{array}{l}\text { Terra cultivada (área e } \\
\text { renda) }\end{array}$ & 98,08 & 0 \\
\hline
\end{tabular}

Fonte: elaborado pelo autor

É importante salientar que, como a escassez dos agrotóxicos gera uma renda (que se incorpora ao seu preço) similar à de um recurso natural, esta renda é subtraída do valor monetário total na determinação do valor agregado, como mostra a expressão (5). No entanto, quando a limitação do uso de agrotóxicos é induzida pela cobrança de impostos (que figuram no problema primal como um acréscimo ao tempo de trabalho), estes incorporam-se diretamente no preço, não se expressando matematicamente como uma renda. O resultado é que, neste caso, o valor agregado fornecido pelo modelo é acrescido do imposto, não sendo equivalente, portanto, ao tempo de trabalho. Para que o cálculo do valor agregado seja exato é necessário que o montante total dos impostos seja subtraído do valor agregado fornecido pelo modelo. Salienta-se que a restrição direta ao uso dos agrotóxicos e a sua limitação por meio da cobrança de impostos provocam o mesmo efeito sobre os preços

Observa-se na tabela 5 que a aplicação da técnica alternativa para a produção da cultura (a) passa a ser responsável por 341,11 unidades da produção, sendo a técnica convencional responsável por 158,89 unidades. Quanto a cultura $(b)$, toda a produção passa a ser obtida pela técnica alternativa. Observa-se na tabela 5 que a diminuição do uso de insumos resultou em uma diminuição do uso de combustíveis que passa de 6970 (conforme a tabela 4) para 6579,4 unidades. O mesmo ocorre com o consumo de petróleo que passa de 15125 para 13138,17 unidades. Por outro lado, a aplicação do imposto de $R \$ 2,26$ reais sobre os agrotóxicos (preço original de $\mathrm{R} \$ 1,00$ ) provoca um aumento significativo do tempo de 
trabalho necessário à produção, o qual se repercute nos preços, os quais têm um aumento de mais de $100 \%$ em relação aos mostrados na tabela 3 .

Na tabela 6 são mostrados os resultados econômicos obtidos pela aplicação de oito unidades de tempo de trabalho, a partir da aplicação de um imposto de 2,26 unidades monetárias por unidade de produto sobre os agrotóxicos (como mostrado na tabela 5).

Tabela 6 - Valor agregado pela aplicação de oito horas de trabalho considerando os preços e as rendas gerados pelo limite ao uso de agrotóxicos de 1634,5 litros.

\begin{tabular}{|c|c|c|c|c|c|c|}
\hline & \multicolumn{2}{|c|}{$\begin{array}{l}\text { Produto de consumo } \\
\text { (a) }\end{array}$} & \multicolumn{2}{|c|}{$\begin{array}{l}\text { Produto de consumo } \\
\text { (b) }\end{array}$} & \multirow[t]{2}{*}{$\begin{array}{c}\text { Agrotó- } \\
\text { xicos }\end{array}$} & \multirow[t]{2}{*}{$\begin{array}{l}\text { Com- } \\
\text { bustível }\end{array}$} \\
\hline & $\begin{array}{c}\text { Técnica } \\
\text { conven- } \\
\text { cional }\end{array}$ & $\begin{array}{c}\text { Técnica } \\
\text { alterna- } \\
\text { tiva }\end{array}$ & $\begin{array}{c}\text { Técnica } \\
\text { conven- } \\
\text { cional }\end{array}$ & $\begin{array}{c}\text { Técnica } \\
\text { alterna- } \\
\text { tiva }\end{array}$ & & \\
\hline Produção & 16 & 1,6 & 6,67 & 1,45 & & \\
\hline $\begin{array}{l}\text { Valor da } \\
\text { produção }\end{array}$ & 243,56 & 24,36 & 91,14 & 19,88 & & \\
\hline Agrotóxicos & 60 & 3,84 & 30,67 & 3,2 & 8 & \\
\hline $\begin{array}{l}\text { Valor dos } \\
\text { agrotóxicos }\end{array}$ & 195,56 & 12,52 & 99,95 & 10,43 & 26,07 & \\
\hline $\begin{array}{l}\text { Imposto sobre } \\
\text { os agrotóxicos }\end{array}$ & & & & & 18,07 & \\
\hline Combustíveis & 200 & 19,2 & 48 & 7,27 & & 40 \\
\hline $\begin{array}{l}\text { Valor dos } \\
\text { combustíveis }\end{array}$ & 40 & 3,84 & 9,6 & 1,45 & & 8 \\
\hline $\begin{array}{l}\text { Renda do } \\
\text { petróleo }\end{array}$ & & & & & 0 & 0 \\
\hline Renda da terra & 0 & 0 & 0 & 0 & & \\
\hline Valor agregado & 8 & 8 & $-18,41$ & 8 & 8 & \\
\hline
\end{tabular}

Coerentemente com os resultados mostrados na tabela 5 , na tabela 6 observa-se que o valor agregado gerado pelas técnicas eficientes (convencional e alternativa para a produção (a) e alternativa para a produção $(b))$ é equivalente ao tempo de trabalho aplicado. É interessante observar que o valor agregado que seria obtido pela aplicação da técnica convencional para a geração do produto $(b)$ é negativo, o que inviabilizaria o emprego desta técnica. Como mostrado na tabela 5 , com as técnicas alternativas, que exigem mais área por produto gerado, a área cultivada (de 98,08 unidades) é próxima da área disponível (de 102,5 unidades). Isto indica que as técnicas alternativas não podem substituir totalmente as técnicas convencionais nas condições definidas no modelo. De fato, a quantidade mínima de agrotóxicos que pode ser empregada seria de 1555 unidades, como pode ser observado na tabela 7. Observa-se nesta tabela que, com a quantidade de agrotóxicos limitada à 1555 unidades, a área cultiva corresponde à área disponível de 102,5 unidades. 
Tabela 7 - Principais resultados obtidos com a solução do modelo considerando um limite ao uso de agrotóxicos de 1555 litros.

\begin{tabular}{lcc}
\hline & $\begin{array}{c}\text { Produção ou consumo } \\
\text { (físico) }\end{array}$ & $\begin{array}{c}\text { Valor, preço ou renda } \\
\text { (monetário) }\end{array}$ \\
\hline Tempo de trabalho e valor & 5465 & 5465 \\
agregado & 100 & \\
Cultura (a) convencional & 400 & 15,22 \\
Cultura (a) alternativa & 0 & 13,67 \\
Cultura (b) convencional & 100 & 3,26 \\
Cultura (b) alternativa & 1555 & 0,2 \\
Agrotóxicos & 6550 & 0 \\
Combustíveis & 12935 & 0 \\
Petróleo & 102,5 & \\
Terra cultivada (área e renda) & & \\
\hline
\end{tabular}

Fonte: elaborado pelo autor

Observa-se também na tabela 7 que neste caso a cultura convencional do produto (a) gera 100 unidades e a cultura alternativa deste mesmo produto, 400 unidades. As 100 unidades demandadas do produto $(b)$ continuariam a ser totalmente asseguradas pelo emprego da técnica alternativa.

Passamos agora a considerar medidas baseadas na definição de uma demanda específica de produtos gerados pelas técnicas alternativas, de forma a provocar uma diferenciação dos preços que estimule a aplicação destas técnicas. Como visto anteriormente a escassez de terra nas condições especificadas no modelo não permite que as técnicas alternativas, que apresentam menores rendimentos por superfície, substituam totalmente as técnicas convencionais. No caso da cobrança de impostos, se esta limitação não for respeitada ela pode provocar um nível excessivo de cobrança de impostos, provocando apenas o aumento dos preços dos produtos, sem contribuir para a diminuição do uso de agrotóxicos. No caso da definição de uma demanda específica de produtos gerados por técnicas alternativas, porém, a não observância da compatibilidade entre os rendimentos proporcionados por estas técnicas e a disponibilidade de terra pode ter consequências mais negativas, podendo provocar um aumento do uso de agrotóxicos. Este resultado é provocado pelo fato de, ao causar uma escassez de terra, uma demanda elevada de produtos gerados por técnicas alternativas implica na aplicação de técnicas com maiores rendimentos, o que, de imediato, é assegurado pelo maior emprego de insumos químicos, dentre os quais os agrotóxicos. Uma demanda exagerada de produtos gerados com técnicas alternativas em um contexto de escassez de terra pode, assim, se tornar incompatível com o potencial produtivo destas técnicas, podendo provocar um uso ainda maior de agrotóxicos por meio das técnicas convencionais.

Para ilustrar este fenômeno foram introduzidas duas modificações no modelo apresentado anteriormente. A primeira é a introdução de duas restrições, uma para cada cultura, que determinam demandas específicas para os produtos gerados com técnicas alternativas. A segunda modificação é a introdução de mais uma técnica para a geração do produto (a), a qual proporciona maior rendimento, mas que utiliza mais insumos, de forma que, nas condições iniciais do modelo descritas anteriormente, ela não é viável economicamente. Esta técnica foi denominada "convencional II", na medida em que representa um aprofundamento da artificialização do processo produtivo característico das técnicas convencionais. As características das técnicas consideradas no modelo são mostradas na tabela 8 . 
Tabela 8 - Características das culturas consideradas para a elaboração do modelo com a técnica convencional II

\begin{tabular}{|c|c|c|c|c|c|}
\hline & \multicolumn{3}{|c|}{ Cultura (a) } & \multicolumn{2}{|c|}{ Cultura (b) } \\
\hline & $\begin{array}{l}\text { Técnica } \\
\text { conven- } \\
\text { cional II }\end{array}$ & $\begin{array}{c}\text { Técnica } \\
\text { conven- } \\
\text { cional }\end{array}$ & $\begin{array}{c}\text { Técnica } \\
\text { alterna- } \\
\text { tiva }\end{array}$ & $\begin{array}{c}\text { Técnica } \\
\text { conven- } \\
\text { cional }\end{array}$ & $\begin{array}{c}\text { Técnica } \\
\text { alter- } \\
\text { nativa }\end{array}$ \\
\hline Tempo de trabalho (h/ha) & 2 & 4 & 25 & 30 & 50 \\
\hline Produção (t/ha) & 10 & 8 & 5 & 25 & 10 \\
\hline Agrotóxicos (I/ha) & 50 & 30 & 12 & 115 & 22 \\
\hline Combustível (I/ha) & 200 & 100 & 60 & 180 & 50 \\
\hline
\end{tabular}

Fonte: elaborado pelo autor

A partir dos dados da tabela 8 foram calculados os coeficientes mostrados na tabela 9 (exceto em relação ao petróleo, cujas necessidades são dadas).

Tabela 9 - Coeficientes do modelo considerando a técnica convencional II para a geração do produto (a)

\begin{tabular}{|c|c|c|c|c|c|c|c|}
\hline & \multicolumn{3}{|c|}{ Cultura (a) } & \multicolumn{2}{|c|}{ Cultura (b) } & \multirow[t]{2}{*}{$\begin{array}{l}\text { Agro- } \\
\text { tóxico }\end{array}$} & \multirow[t]{2}{*}{$\begin{array}{c}\text { Com- } \\
\text { bustível }\end{array}$} \\
\hline & $\begin{array}{l}\text { Técnica } \\
\text { conven- } \\
\text { cional II }\end{array}$ & $\begin{array}{l}\text { Técnica } \\
\text { conven- } \\
\text { cional } \\
\end{array}$ & $\begin{array}{c}\text { Técnica } \\
\text { alter- } \\
\text { nativa } \\
\end{array}$ & $\begin{array}{c}\text { Técnica } \\
\text { conven- } \\
\text { cional } \\
\end{array}$ & $\begin{array}{l}\text { Técnica } \\
\text { alter- } \\
\text { nativa } \\
\end{array}$ & & \\
\hline $\begin{array}{l}\text { Tempo de } \\
\text { trabalho }(\mathrm{h} / \mathrm{t})\end{array}$ & 0,2 & 0,2 & 5 & 1,2 & 5,5 & 1 & 0,2 \\
\hline $\begin{array}{l}\text { Agrotóxico } \\
(\mathrm{l} / \mathrm{t})\end{array}$ & 5 & 3,75 & 2,4 & 4,6 & 2,2 & & \\
\hline $\begin{array}{l}\text { Combustível } \\
(\mathrm{l} / \mathrm{t})\end{array}$ & 20 & 12,5 & 12 & 7,2 & 5 & & \\
\hline Petróleo (I/I) & & & & & & 2 & 1,5 \\
\hline Terra (ha/t) & 0,1 & 0,125 & 0,2 & 0,04 & 0,1 & & \\
\hline
\end{tabular}

Fonte: elaborado pelo autor

Com as modificações realizadas no modelo foi calculada novamente a sua solução sem restrições de recursos naturais, considerando uma demanda específica de 410 e 85 unidades dos produtos $(a)$ e $(b)$, respectivamente, gerados com técnicas alternativas. Os principais resultados fornecidos pela solução são mostrados na tabela 10.

Observa-se na tabela 10 que a técnica convencional II não é empregada para a geração do produto (a). Além disto, observa-se também nesta tabela que os preços dos produtos gerados com técnicas alternativas são mais elevados do que os gerados com as técnicas convencionais. Essas diferenças de preço são explicadas pela existência das demandas específicas de produtos gerados com técnicas alternativas. 
Tabela 10 - Principais resultados obtidos com a solução do modelo considerando demandas específicas de 410 e 85 unidades dos produtos (a) e (b) gerados com as técnicas alternativas

\begin{tabular}{lcc}
\hline & $\begin{array}{c}\text { Produção ou } \\
\text { consumo (físico) }\end{array}$ & $\begin{array}{c}\text { Valor, preço ou } \\
\text { renda (monetário) }\end{array}$ \\
\hline Tempo de trabalho e valor agregado & 5473,6 & 5473,6 \\
Cultura (a) convencional & 0 & 6,75 \\
Cultura (a) alternativa & 90 & 9,8 \\
Cultura (b) convencional & 410 & 7,24 \\
Cultura (b) alternativa & 15 & 8,7 \\
Cultura (a) convencional & 85 & 1 \\
Agrotóxicos & 1577,5 & 0,2 \\
Combustíveis & 6578 & 0 \\
Petróleo & 13022 & 0 \\
Terra cultivada (área e renda) & 102,35 & \\
\hline
\end{tabular}

Fonte: elaborado pelo autor

O valor agregado obtido pela aplicação de oito unidades de tempo de trabalho nas mesmas condições em que foram obtidos os resultados mostrados na tabela 10 é mostrado na tabela 11. Observa-se nesta tabela que a cultura convencional II proporcionaria um valor agregado bastante negativo, o que mostra que ela se encontra longe da base ótima, sendo inviável economicamente mesmo sem restrições de petróleo e de terra.

Tabela 11 - Valor agregado pela aplicação de oito horas de trabalho considerando demandas específicas de 410 e 85 unidades dos produtos $(a)$ e $(b)$, respectivamente, gerados com técnicas alternativas.

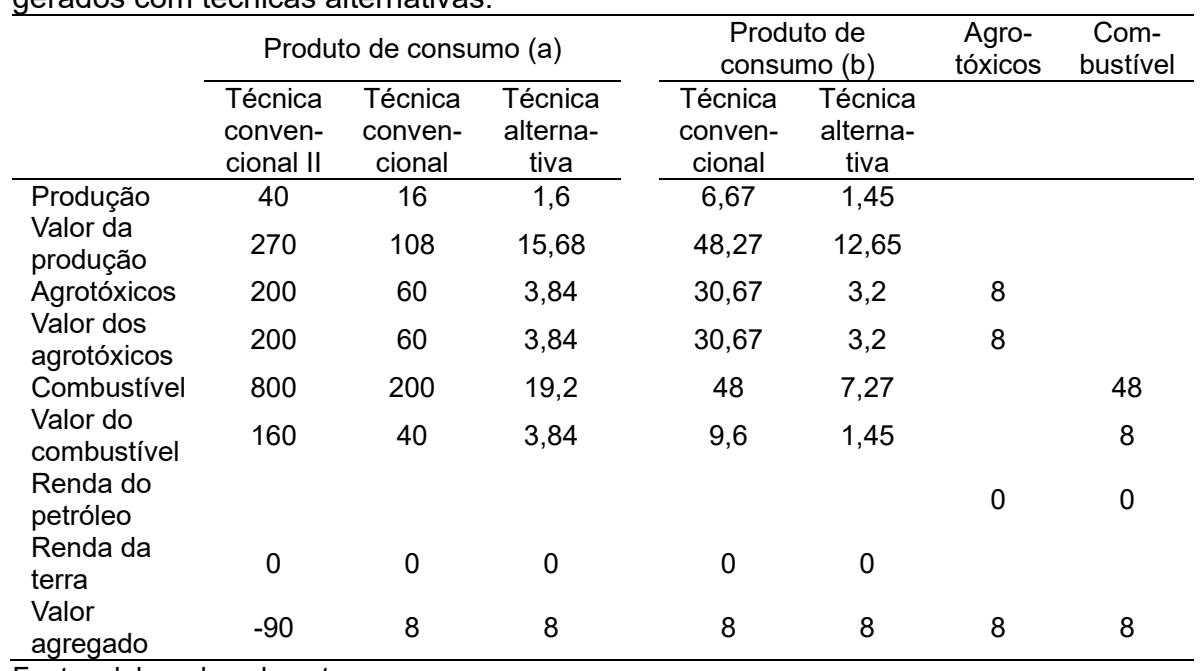

Fonte: elaborado pelo autor

No entanto, esses resultados mudam radicalmente se a demanda específica de produtos gerados com técnicas alternativas ultrapassa certo limite. Para evidenciar este fenômeno, foi realizada nova simulação considerando uma demanda de 425 e 90 unidades dos produtos $(a)$ e $(b)$, respectivamente, gerados pelas técnicas alternativas. Os principais resultados obtidos com a solução do modelo são mostrados na tabela 12. Observa-se nesta tabela que a cultura convencional II entra na base 
ótima, sendo responsável por 51 unidades produzidas, sendo que a cultura convencional passa a gerar 24 unidades. A entrada da cultura convencional II na base ótima explica-se pela escassez de terra, o que pode ser constatado pelo total da área cultivada corresponder à área disponível, assim como pela existência de uma elevada renda da terra, de 98 unidades, como observa-se na tabela 12. Também neste caso, observa-se na tabela 12 que os preços dos produtos gerados com técnicas alternativas são mais elevados do que os gerados com as técnicas convencionais devido as demandas específicas de produtos gerados com técnicas alternativas.

Tabela 12 - Principais resultados obtidos com a solução do modelo considerando demandas específicas de 425 e 90 unidades dos produtos $(a)$ e $(b)$ gerados com as técnicas alternativas

\begin{tabular}{lcc}
\hline & $\begin{array}{c}\text { Produção ou } \\
\text { consumo (físico) }\end{array}$ & $\begin{array}{c}\text { Valor, preço ou renda } \\
\text { (monetário) }\end{array}$ \\
\hline Tempo de trabalho e valor agregado & 5651,6 & 5651,6 \\
Cultura (a) convencional & 51 & 19 \\
Cultura (a) alternativa & 24 & 29,4 \\
Cultura (b) convencional & 425 & 11,16 \\
Cultura (b) alternativa & 10 & 18,5 \\
Cultura (a) convencional & 90 & 1 \\
Agrotóxicos & 1609 & 0,2 \\
Combustíveis & 6942 & 0 \\
Petróleo & 13631,5 & 98 \\
Terra cultivada (área e renda) & 102,5 & \\
\hline
\end{tabular}

Fonte: elaborado pelo autor

Por outro lado, a definição de demandas específicas para os produtos alternativos, no nível em que foram fixadas, provocou uma significativa diminuição do uso de agrotóxicos em relação às condições iniciais (de 2335 para 1609 unidades), como pode ser observado pela comparação das tabelas 3 e 12. Este efeito, no entanto, foi bem menos pronunciado no caso dos combustíveis, cujo consumo diminuiu de 6970 para 6942 unidades (ver tabelas 3 e 12).

Na tabela 13 são apresentados os resultados obtidos a partir da aplicação de oito unidades de tempo de trabalho nas atividades consideradas no modelo, de acordo com os resultados mostrados na tabela 12. Observa-se nesta tabela que, com a escassez de terra provocada pela excessiva demanda específica dos produtos alternativos, todas as técnicas tornam-se eficientes, o que pode ser constatado pelo montante do valor agregado ser equivalente ao número de unidades de tempo de trabalho aplicadas. É interessante salientar, assim, que a cultura convencional II, cujo elevado consumo de agrotóxicos e combustíveis a tornava inviável em condições de abundância de petróleo e de terra, passa a se tornar viável economicamente devido ao fato da elevada demanda de produtos gerados pelas técnicas alternativas não permitirem que a demanda seja satisfeita sem a intensificação do uso de insumos para a obtenção de maiores rendimentos por área. Além disto, como observa-se na tabela 13 , a escassez de terra gera rendas que são muito mais elevadas no caso das culturas convencionais, principalmente a II, do que no caso das culturas alternativas. Isto implica que, se as rendas geradas pela escassez de terras forem apropriadas nas unidades de produção, somando-se ao valor agregado, elas estimulariam muito mais as técnicas convencionais, especialmente as que empregariam mais insumos químicos, do que as alternativas. 
Tabela 13 - Valor agregado pela aplicação de oito horas de trabalho considerando demandas específicas de 425 e 90 unidades dos produtos $(a)$ e $(b)$, respectivamente, gerados com técnicas alternativas.

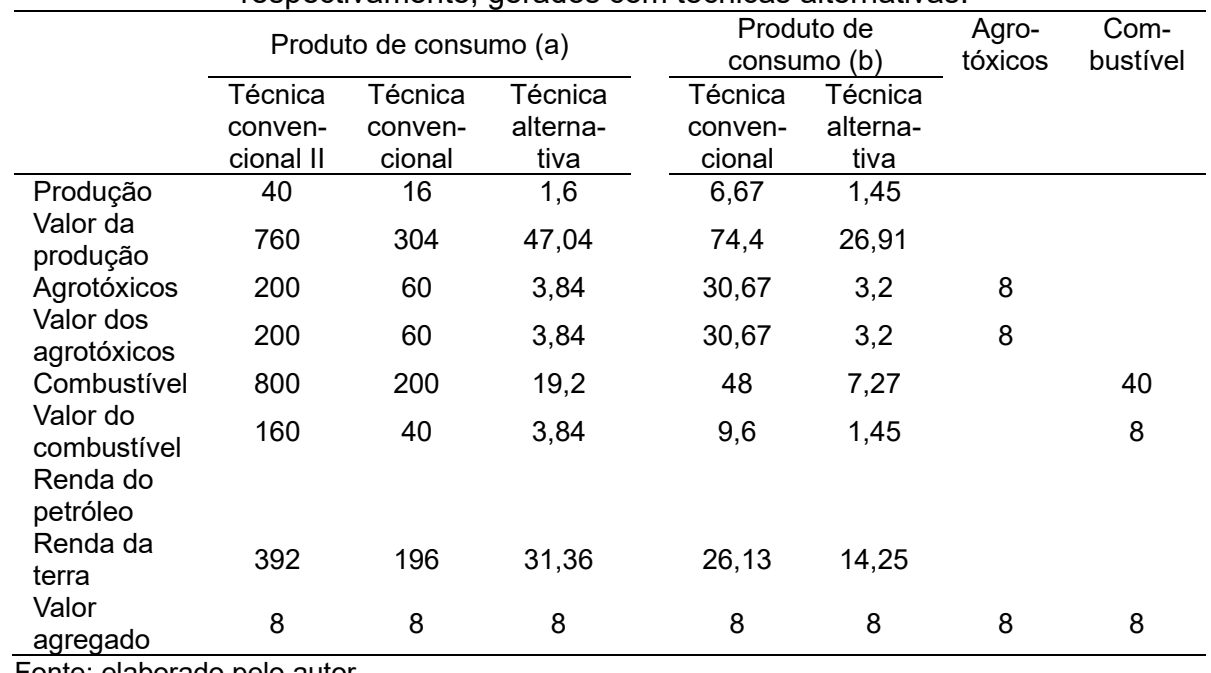

Fonte: elaborado pelo autor

Os resultados mostrados nas tabelas 12 e 13 mostram que a definição de demandas específicas pode podem levar a um aumento do uso de insumos químicos na agricultura, caso a demanda dos produtos alternativos ultrapasse certo limite, definido pela área disponível, especialmente no caso das rendas serem apropriadas pelos agricultores, como normalmente ocorre. Ultrapassado este limite, além de poderem provocar o aumento do uso de insumos químicos, as demandas específicas provocam um aumento do preço do produto alternativo bem mais acentuado do que $o$ do produto gerado pelas culturas convencionais.

Por outro lado, pode-se alegar que a qualidade sanitária e nutricional superior, além da menor agressão ao ambiente, decorrente do menor uso de agrotóxicos pelo produto alternativo justificaria o seu sobre preço. Neste sentido, tal sobre preço não implicaria apenas em um aumento do valor monetário, mas também em um efetivo aumento de riqueza. Por outro lado, é importante observar que tal geração de riqueza não permite que mais pessoas possam ser alimentadas, com a demanda total do produto permanecendo a mesma. Neste caso, a definição de demandas específicas forçosamente se destinaria apenas a uma parte da população, normalmente a que possui maior poder aquisitivo.

Assim, a possibilidade do aumento do uso de insumos químicos e o caráter socialmente excludente que pode assumir uma política de discriminação dos produtos alternativos em relação aos convencionais revelam possíveis contradições de algumas medidas comumente protagonizadas, que pregam a promoção de uma mudança tecnológica global na agricultura por meio do estímulo a demandas específicas de produtos gerados com técnicas alternativas.

Neste sentido, é interessante observar que os resultados obtidos também infirmam certas concepções, um tanto simplistas, de que a promoção da agricultura familiar e da sustentabilidade possam ser determinadas a partir e um aumento indiscriminado da demanda dos consumidores por produtos com características específicas impulsionado por políticas públicas, processo por vezes denominado de "construção de mercados" (MARQUES et al., 2016). Ocorre que esses "novos 
mercados", embora possam beneficiar certos agricultores, podem refletir apenas os interesses de classes sociais com maior poder aquisitivo em consumir alimentos mais saudáveis (SILVA NETO, 2019). Isto reforça a necessidade de uma planificação ecológica da agricultura que seja baseada em conhecimentos suficientemente precisos da realidade agrária e, principalmente, que seja resultante de um debate democrático que esclareça efetivamente os interesses de classe envolvidos.

Um inconveniente do estabelecimento de preços diferentes para um mesmo produto, baseando a diferenciação dos preços nas suas técnicas de produção, é que isto exige sistemas de certificação que garantam que os produtos foram efetivamente produzidos por meio das técnicas que se pretende estimular. Muitas vezes, tal exigência se traduz na implantação de sistemas de certificação que podem limitar severamente a autonomia dos agricultores na escolha das técnicas mais adequadas às suas condições (SILVA NETO, 2019).

É importante observar também que, para que uma política de preços possa ser implantada de forma efetiva a execução das medidas necessárias para a determinação dos preços dos meios de produção (como a cobrança de impostos) e o pagamento pelos produtos finais, devem ser assegurados pelo Estado. Conforme discutido por alguns autores isto implicaria na criação de um setor público de produção não regulado pelo mercado (HARRIBEY, 2004; SILVA NETO, 2016). Uma das características mais importantes deste setor, salientadas por estes autores, é que ele, ao gerar valor agregado, não depende economicamente do setor privado, embora suas atividades limitem as relações mercantis. Assim, a instituição desse setor estatal não pode ser considerada como um processo de "construção de mercados", como afirmam vários autores, na medida em que os preços não são formados por meio do mercado (MARQUES et. al., 2016). Ao contrário, tais políticas implicam na limitação das relações mercantis em grande parte responsáveis pela formação dos preços nas sociedades contemporâneas.

Enfim, salientamos o caráter meramente ilustrativo do exemplo numérico elaborado. Uma efetiva planificação ecológica da agricultura requer a elaboração de modelos de grandes dimensões com coeficientes calculados a partir de sólidos estudos realizados especialmente em condições de campo, nos quais a extensão rural pode desempenhar um papel fundamental. Além disto, salientamos que o modelo não prevê possíveis alterações nas técnicas de produção. Por outro lado, o modelo pode ser empregado para estimar o aumento da produtividade necessário para proporcionar maior robustez a viabilidade econômica das técnicas mais desejáveis e, assim, servir para orientar pesquisas para tornar o desenvolvimento tecnológico da agricultura mais compatível com a sua sustentabilidade.

\section{CONSIDERAÇÕES FINAIS}

De acordo com o exposto na introdução, este trabalho tem o objetivo de demonstrar que uma planificação ecológica pode se constituir em uma forma eficiente de conduzir um debate democrático sobre os padrões tecnológicos mais adequados para a promoção da sustentabilidade da agricultura. Os resultados apresentados evidenciam que o modelo apresentado é compatível com tal planificação. A consideração das riquezas sociais como variáveis exógenas, cujos valores devem ser definidos por decisões políticas, a partir das quais podem ser definidos preços eficientes, é o que permite esta compatibilidade. Fica claro, assim, que a questão da sustentabilidade em grande parte depende das decisões fundamentais que uma sociedade toma sobre as suas riquezas materiais.

Neste sentido, pelo menos três condições devem ser respeitadas para a implantação de uma planificação ecológica democrática e eficiente da agricultura. A 
primeira condição diz respeito à necessidade de um conhecimento objetivo e suficientemente aprofundado, obtido principalmente em condições de campo, que permita uma avaliação precisa da capacidade das técnicas disponíveis de responderem aos objetivos fixados. Salientamos que a extensão rural pode desempenhar um papel fundamental na execução desses estudos. A segunda condição é que os problemas sociais e ecológicos relacionados à agricultura sejam avaliados objetivamente a partir de uma perspectiva global e interdisciplinar, retirando o caráter normativo que, segundo as concepções correntes (como em STIGLITZ; WALSH, 2003, p. 171-174) a economia deve desempenhar na definição da alocação de recursos e na distribuição das riquezas. A terceira condição, a mais importante, é que o acesso às riquezas sociais seja definido a partir de processos genuinamente democráticos, na medida em que, conforme mostrado por meio do modelo apresentado no artigo, as decisões fundamentais sobre as riquezas tomadas no conjunto da sociedade dependem de processos extra econômicos cujos resultados não podem ser determinados pela planificação. Ao contrário, é a partir da definição do acesso às riquezas sociais, resultante fundamentalmente da luta de classes, é que uma planificação pode ser implementada. Isto implica na necessidade de uma firme oposição ao poder econômico que assegura aos capitalistas um acesso privilegiado às riquezas sociais. Somente nessas condições é que se pode colocar em prática uma efetiva, pois radicalmente democrática, planificação ecológica da agricultura.

Por outro lado, salientamos que os resultados obtidos neste trabalho de forma alguma indicam que a simples aplicação do modelo seria capaz de assegurar uma planificação democrática. Isto porque a democratização das decisões sobre as riquezas é indissociável das lutas sociais que se contrapõem ao padrão tecnológico concentrador da riqueza e destruidor do ambiente protagonizado pelo agronegócio. Por outro lado, o modelo de planificação apresentado no trabalho pode contribuir para uma análise mais precisa e objetiva das condições atuais para a superação de tal padrão tecnológico, proporcionando uma fundamentação racional para a reivindicação de intervenções do Estado como, por exemplo, a implantação de políticas de pesquisa e de extensão que permitam desenvolver técnicas mais sustentáveis que proporcionem maiores rendimentos por superfície e maior produtividade do trabalho. Neste sentido, a partir deste artigo, de caráter mais técnico, uma perspectiva que se coloca para trabalhos futuros a serem realizados com base nos seus resultados é a análise das controvérsias intelectuais e políticas acerca da planificação, considerando o debate existente sobre as relações entre marxismo e ecologia.

\section{REFERÊNCIAS}

BIHOUIX, P. L'Age des low tech. Vers une civilization techniquement soutenable. Paris: Seuil, 2014.

BILLARD, M. (coord.) Face à l'urgence climatique, la planification écologique. Les livrets de la France insoumise, número 6, 2016. Disponível em: https://avenirencommun.fr/livrets-thematiques/livret-planification-ecologique-regleverte/. Acesso: 14 fev. 2020.

GUERRIEN, B. La théorie néo-classique. Bilan et perspectives du modèle d'équilibre général. Paris: Économica, 1989. 
HARRIBEY, J.-M. Le travail productif dans les services non marchands: un enjeu théorique et politique. Economie appliquée, an international journal of economic analysis, Tomo LVII, n. 4, p. 59-96, dez. 2004.

HUSSON, M. De l'economie socialiste à la planification écologique. A l'encontre. Juillet 2019. Disponível em http://alencontre.org/ecologie/de-leconomie-dusocialisme-a-la-planification-ecologique.html. Acesso em: 03 mar. 2020.

LÉVARD, L. (coord.) Une agriculture paysanne \& écologique pour une alimentation de qualité. Les livrets de la France insoumise, $\mathrm{n}^{\circ} 1$, 2016. Disponível em https://avenirencommun.fr/livrets-thematiques/livret-agriculture/. Acesso: 14 fev. 2020.

LÖWY, M. Écosocialisme et planification démocratique. Écologie \& politique. n. 37, v. 3, p. 165-180, 2008.

LUKÁCS, G. Prolegomènes à l'ontologie de l'être social. Paris: Éd. Delga, 2009.

LUKÁCS, G. Ontologie de l'être social. Le travail, la reproduction. Paris: Éd. Delga, 2011.

MARQUES, F. C.; CONTERATO, M. A.; SCHNEIDER, S. (Org.) Construção de mercados e agricultura familiar: desafios para o desenvolvimento rural. Porto Alegre: Editora da UFRGS, 2016.

MARX, K. Capital: critique of Political Economy. Volume I. Nova York: International Publishers, 2010 [1867].

SILVA NETO, B. A Agroecologia na dinâmica do desenvolvimento rural do Norte e Noroeste do Rio Grande do Sul: o papel das instituições locais e a integração da Universidade Federal da Fronteira Sul neste processo. Relatório Técnico MDA/SAF/CNPq - Edital 58/2010 - Chamada 2, 2013. Disponível em https://beneweb.com.br. Acesso em: 22 jun. 2020.

SILVA NETO, B. Riqueza, valor e políticas públicas para a promoção da Agroecologia. Revista Brasileira de Agroecologia, v.11 n.4, p. 378-389, 2016.

SILVA NETO, B. A questão agroecológica: uma perspectiva ecossocialista. Curitiba: Ed. CRV, 2017.

SILVA NETO, B. A promoção do desenvolvimento sustentável e a teoria marxista dos preços. A importância das rendas diferenciais na teoria dos preços de Marx. Desenvolvimento em Questão, ano 16, n. 44, p. 9-41, jul./set 2018.

SILVA NETO, B. Agroecologia e classes sociais: uma abordagem baseada nas obras de György Lukács e Michel Clouscard. Ambiente \& Sociedade, São Paulo. v. 22, p. 1-18, 2019.

STIGLITZ. J. E.; WALSH, C. E. Introdução à microeconomia. Rio de Janeiro: Ed. Campus, 2003. 
TOMJO. L'Enfer vert: un projet pavé de bonnes intentions, suivi de Critique de la planification écologique. Montreuil: L’Echappée, 2013. (Collection Négatif). 